\title{
DON'T RAISE THE RETIREMENT AGE! AN EXPERIMENT ON OPPOSITION TO PENSION REFORMS AND EAST-WEST DIFFERENCES IN GERMANY
}

Beatrice Scheubel, Daniel Schunk and Joachim Winter 


\title{
Don't raise the retirement age! \\ An experiment on opposition to pension reforms and East-West differences in Germany *
}

\author{
Beatrice Scheubel** Daniel SchunK ${ }^{\S} \quad$ JoAchim Winter $^{\ddagger}$
}

This version: August 2009

\begin{abstract}
For policy reforms to increase a society's welfare, reliable information on people's preferences and expectations is crucial. Representative opinion polls, often involving simplified questions about the complex topics under debate, are an important source of information for both policy-makers and the public. Do people's answers to these poll questions reliably reflect their preferences and expectations, or does fundamental, undiscriminating opposition to reforms distort them? We address this question in the context of a recent German pension reform which raised the statutory retirement age by two years to age 67 . By introducing an experiment into a representative household survey, we are able to disentangle expectations of work ability at retirement and fundamental opposition. Our results show that expected work ability declines substantially with increasing target age (63, 65, or 67 years). Answers from West German respondents reflect their current life situation as well as individual health and other risk factors. However, a fundamental opposition to reforms of the welfare state appears to strongly affect responses from East German households.
\end{abstract}

Keywords: retirement; health; work ability; survey experiment; public opinion poll; PAYG pension system; East Germany.

JEL-Codes: J10, H30, H55, D84

${ }^{*}$ The authors would like to thank Robert Fenge, Michael Haliassos, Ray Rees, Anno Stolper, and Hans-Werner Sinn as well as participants at IIPF 2008 Annual Conference, Maastricht for helpful comments and suggestions. Financial Support from the German National Research Foundation (DFG) is gratefully acknowledged.

${ }^{* *}$ Center for Economic Studies, University of Munich. Address: Schackstr. 4, 80539 Munich, Germany. Phone: +49-89-2180-3763. Fax: +49-89-397303. Email: scheubel@lmu.de.

${ }^{\S}$ Corresponding author. Institute for Empirical Research in Economics, University of Zürich. Address: Blümlisalpstr. 10, CH-8006 Zürich, Switzerland. Phone: +41-44-634-3704. Fax: +41-44-634-4907. Email: dschunk@iew.uzh.ch.

${ }^{\ddagger}$ Department of Economics, University of Munich. Address: Ludwigstr. 28 RG, 80539 Munich, Germany. Phone: +49-89-2180-2459. Fax: +49-89-2180-3954. Email: winter@lmu.de. 


\section{Introduction}

Information obtained from opinion polls is crucial for decisions on the design and implementation of policies (Page and Shapiro 1984; Cukierman 1991; Morwitz and Pluzinski 1996; Bütler 2000, 2002). Opinion polls provide important guidance for political decision-makers and stimulate the interaction between theoretical and empirical researchers, thus enriching the policy discourse. In many political discussions about welfare reforms, negative opinion poll results are taken as an important argument against changes, encouraging some politicians to object the reform. After all, so the argument goes, opinion polls are often the only between-election possibility for voicing general and credible discontentment with politics and politicians in representative democracies. In contrast, proponents of a reform may hold the view that information obtained from opinion polls is unreliable and should not be taken as an important argument in the debate about reform proposals.

The issue underlying these two different views about the relevance of opinion poll data is the question whether opinion polls reflect people's preferences and expectations with respect to specific reform proposals, or whether fundamental opposition to reforms distorts them. Polls on pension reforms are prominent examples of such contested surveys, illustrating the importance of opinion pools and the controversy surrounding them. Public opposition against pension reforms is pronounced, both in the United States and in Europe (Burtless and Quinn 2000; Boeri et al. 2002; Börsch-Supan et al. 2004). As an example, consider the German pension reform in 2007, which raised the statutory retirement age by two years to age $67 .{ }^{1}$ Representative opinion polls such as those shown in Figure 1 suggest that $70 \%$ of the population in former West Germany and $80 \%$ of the population in former East Germany opposed the reform.

[Figure 1 about here]

\footnotetext{
${ }^{1}$ Details on the German pension system and the reform can be found in the appendix in section A.1.
} 
In this paper, we use a unique survey experiment to provide evidence that fundamental opposition to reforms of the welfare state is reflected in survey responses. We do so by showing that survey responses are not driven by the underlying fundamentals such as expectations or preferences - but rather by an unwillingness to accept changes in the status quo. Thus, the paper challenges an important assumption of many policymakers, namely that acting according to the opinion expressed in representative polls is in the best interest of a society's welfare.

We use the German pension reform of 2007 mentioned above as an example and focus on the main argument raised against its implementation: people's fear of low work ability as they approach retirement, as stated frequently in opinion polls. Specifically, our study sheds light on the following two questions: (i) is the expression of those fears of low work ability driven by people's underlying expectations about their future health and, (ii) to what extent is it driven by fundamental opposition to the pension reform? Generally, we find that work ability expectations vary meaningfully with individual risk factors and are not generally driven by fundamental opposition to reforms. This finding does not, however, apply to former communist East Germany. Our data provide evidence that fundamental opposition considerably affects people's survey responses in East Germany. This is in line with the recent literature on the impact of communism on people's preferences and behavior (Ockenfels and Weimann 1999; Alesina and FuchsSchündeln 2007).

Our experiment asked the survey respondents for their expectations of work ability at one specific target age; the target age at which expected work ability was to be rated was assigned randomly (63, 65, or 67 years). The specific age is the only parameter that differs between the three randomly assigned groups. Only one of the groups is asked to state expected work ability at the age of 67 , which implies a change in the status quo of the pension system. By controlling for the determinants of true work ability expectations, we can identify whether there is residual variation in answers and whether this residual variation is significantly different in the group that is exposed to the experimental condition associated with a change in the status quo. Of course, 
in order to achieve our goal of separating fundamental opposition to reforms from underlying expectations, fully controlling for other determinants of retirement behavior is crucial. These determinants involve potential financial incentives for early or late retirement, income, wealth, savings flows, risk and time preferences, as well as sociodemographic characteristics, health and life style in the specific context of the work ability argument we investigate. Detailed individual-level data on these variables are typically not available for opinion polls. Our experiment was therefore embedded into a representative household panel survey which includes all this information. Moreover, we augment our survey data with administrative data on public pension entitlements.

Our work contributes to several distinct literatures. First, the increasing use of survey data for empirical research raises questions about the reliability of individual appraisals and subjective assessments (Bertrand and Mullainathan 2001). In particular, there is increasing interest in measuring individual expectations (Manski 2004), in how these expectations are formed, and in whether they are formed rationally (BenítezSilva et al. 2008). Our study analyzes the potential bias in stated expectations when there is the possibility of fundamental opposition to policies. Given the association between individual expectations and actual retirement behavior - see, e.g., McGarry (2004) and O'Donnell et al. (2008) - finding out more about how these expectations are formed thus helps to judge the feasibility of pension reforms.

Second, our work contributes to the literature on how to reform public Pay-As-YouGo (PAYG) pension systems in the wake of demographic change (e.g., Börsch-Supan 2003, 2004) and how to win political and public support for such reforms (Boeri and Tabellini 2008). While raising the retirement age has long been considered the most logical reform option for sustaining PAYG pension systems, the reasons why a large fraction of the population does not support this reform option in so many countries are less clear. Our experimental manipulation demonstrates clearly that many respondents indeed believe they will become progressively less fit to work as they age and expect a strongly negative work ability gradient between 63 and 67. Thus, if policy-makers would like reforms, which raise the retirement age, to succeed, they have to address 
these concerns in order to mitigate the most important reform objections.

Finally, our results contribute to the literature on work ability. Controlling for between-group variation in a multivariate regression analysis, we show that coefficients of individual risk factors such as health, satisfaction with work, or life expectancy are significant determinants of expected work ability. Thus, the results of our survey experiment corroborate findings in the medical literature on the determinants of work ability (e.g. Tuomi et al. 2001).

The paper is laid out as follows. In section 2, we present a stylized model of government and individual behavior that rationalizes a bias in publicly stated expectations about work ability at the retirement age. We discuss the design of our experiment and the household survey in which it was implemented in section 3. Section 4 contains our regression results and several sensitivity analyses. Section 5 concludes.

\section{Theoretical framework}

In this section, we present a simple theoretical model, part of which builds on a setup used in Diamond and Mirrlees (1978). The purpose is to show that when the government chooses the statutory retirement age based on health signals, individuals may have an incentive to send a false signal about their health expectations if they derive additional utility from preserving the status quo. Thus, if the government ignored the fact that the health signal is actually distorted because individuals fundamentally oppose the reform, it would choose a retirement age that would be lower than the retirement age that would be in the interest of the society.

\section{$2.1 \quad$ Setup}

Consider an economy with a government and a continuum of individuals. Each individual lives for one period. The government and the individuals make decisions at the beginning of the period. An individual is either healthy or unhealthy for the whole period. Individuals do not know their health type at the beginning of the period. At this 
stage they can, however, form expectations about their health type. Individuals signal their expectations about their health type to the government. Based on the health signal, the government then chooses a uniform statutory retirement age, so that each individual spends a fraction $r$ working and is retired for fraction $1-r .^{2}$

There are three stages of decision-making at the beginning of the period. At stage 1 , the government sets the tax rate $\tau$ which is used to finance flat-rate pensions. At stage 2, individuals form expectations about their health type and send a signal about their type to the government. At stage 3 , the government sets the statutory retirement age. As the focus of our experiment is the bias in the individual signal, we present only the analysis of stages 3 and 2 in detail.

Let $\theta_{i}$ denote the individual probability of being the healthy type. The individual signal of the probability of being healthy is denoted by $\hat{\theta}_{i}$. The continuum of individuals is normalized to unity, such that the ex ante probability distribution of healthy individuals translates into the composition of the population of healthy and unhealthy individuals. There is a fraction $\theta_{i}$ of healthy individuals and a fraction $\left(1-\theta_{i}\right)$ of unhealthy individuals.

An individual earns wage $w$ for each unit of output. If working life is of length $r$, the individual produces $r$ units of output. If an individual is unhealthy, he is able to work, but will have a lower productivity. For convenience, we normalize the wage to $w_{H}=1$ if an individual is healthy and to $w_{L}=\frac{1}{2}$ if an individual is unhealthy.

Let $c$ denote consumption. Consumption in working life must be financed by disposable income, $(1-\tau) w r$. Let $c_{1}$ denote consumption if the individual is healthy. $c_{1}$ is hence given by

$$
c_{1}=(1-\tau) r .
$$

Let $c_{2}$ denote consumption if the individual is unhealthy. $c_{2}$ is hence given by

$$
c_{2}=(1-\tau) \frac{r}{2}
$$

\footnotetext{
${ }^{2}$ By uniform we mean that the government does not set different retirement ages for healthy and ill individuals.
} 
For the fraction $1-r$, the government pays the transfer $c_{3}$, which is financed with tax revenue. $c_{3}$ is hence given by

$$
c_{3}=\theta_{i}(\tau r)+\left(1-\theta_{i}\right)\left(\tau \frac{r}{2}\right) .
$$

There is no private saving in the economy.

An individual derives utility $u_{1}(c)$ when working and $u_{2}(c)$ when not working. We assume a disutility of work component in $u_{1}$, such that $u_{2}(c) \geq u_{1}(c) \forall c$. The utility functions are assumed to possess the usual properties. We assume that there is additional utility attached to the state of being retired instead of working. This utility, $u_{R}\left(o_{i}\right)$, is only realized when the individual does not work. It depends on an individual preference parameter which we denote by $o_{i}$. This parameter captures the additional utility attached to preserving the status quo retirement age, and the higher $o_{i}$, the higher the utility from being retired, $\frac{\partial u_{R}\left(o_{i}\right)}{\partial o_{i}}>0$.

Given the proportion $\theta_{i}$ of healthy individuals, once the tax rate $\tau$ and thus consumption levels when working, $c_{1}$ and $c_{2}$, are set, the distribution of consumption between working and non-working life can only be affected via the length of working life $r$. This relationship between $r$ and $c_{3}$ is reflected in the ex ante individual budget constraint, i.e. before the health type is revealed, which equates total lifetime income with total lifetime consumption:

$$
\theta_{i}[r(1-\tau)]+\left(1-\theta_{i}\right)\left[\frac{r}{2}(1-\tau)\right]=r\left[\theta_{i} c_{1}+\left(1-\theta_{i}\right) c_{2}\right]+(1-r) c_{3}\left(\tau, \theta_{i}, r\right) .
$$

Expected lifetime utility for individual $i$ is then given by

$$
v_{i}(r)=r\left[\theta_{i} u_{1}\left(c_{1}\right)+\left(1-\theta_{i}\right) u_{1}\left(c_{2}\right)\right]+(1-r)\left[u_{2}\left(c_{3}\right)+u_{R}\left(o_{i}\right)\right] .
$$

\subsection{The government's choice of the retirement age $r$}

When the government decides on the optimal retirement age (i.e. the length of working life, $r$ ), it takes into account the tax rate $\tau$ it set at the first stage and the health signal $\hat{\theta}_{i}$, which the individuals sent at the second stage. The opposition parameter $o_{i}$ is 
unobserved and not taken into account when choosing the optimal length of working life. The government chooses the optimal length of working life according to

$$
v^{G}=\hat{\theta}_{i}\left[r u_{1}\left(c_{1}\right)+(1-r) u_{2}\left(c_{3}\right)\right]+\left(1-\hat{\theta}_{i}\right)\left[r u_{1}\left(c_{2}\right)+(1-r) u_{2}\left(c_{3}\right)\right],
$$

subject to the following constraints:

$$
\begin{aligned}
c_{1} & =(1-\tau) r \\
c_{2} & =(1-\tau) \frac{r}{2} \\
c_{3} & =\theta_{i} \tau r+\left(1-\theta_{i}\right) \tau \frac{r}{2} .
\end{aligned}
$$

If individuals signal their true expectation $\theta_{i}=\hat{\theta}_{i}$, the government will choose a higher retirement age than individuals would prefer. The government chooses the optimal retirement age according to

$$
\begin{gathered}
\hat{\theta}_{i}^{*}\left[u_{1}\left(c_{1}\right)-u_{2}\left(c_{3}\right)+\frac{\partial u_{2}}{\partial c_{3}} \frac{\partial c_{3}}{\partial r}+r\left(\frac{\partial u_{1}}{\partial c_{1}} \frac{\partial c_{1}}{\partial r}-\frac{\partial u_{2}}{\partial c_{3}} \frac{\partial c_{3}}{\partial r}\right)\right] \\
= \\
\left(1-\hat{\theta}_{i}^{*}\right)\left[u_{2}\left(c_{3}\right)-u_{1}\left(c_{2}\right)-\frac{\partial u_{2}}{\partial c_{3}} \frac{\partial c_{3}}{\partial r}-r\left(\frac{\partial u_{1}}{\partial c_{2}} \frac{\partial c_{2}}{\partial r}-\frac{\partial u_{2}}{\partial c_{3}} \frac{\partial c_{3}}{\partial r}\right)\right],
\end{gathered}
$$

while the individual would prefer a choice according to

$$
\begin{gathered}
\theta_{i}^{*}\left[u_{1}\left(c_{1}\right)-u_{2}\left(c_{3}\right)-u_{R}\left(o_{i}\right)+\frac{\partial u_{2}}{\partial c_{3}} \frac{\partial c_{3}}{\partial r}+r\left(\frac{\partial u_{1}}{\partial c_{1}} \frac{\partial c_{1}}{\partial r}-\frac{\partial u_{2}}{\partial c_{3}} \frac{\partial c_{3}}{\partial r}\right)\right] \\
= \\
\left(1-\theta_{i}^{*}\right)\left[u_{2}\left(c_{3}\right)-u_{1}\left(c_{2}\right)+u_{R}\left(o_{i}\right)-\frac{\partial u_{2}}{\partial c_{3}} \frac{\partial c_{3}}{\partial r}-r\left(\frac{\partial u_{1}}{\partial c_{2}} \frac{\partial c_{2}}{\partial r}-\frac{\partial u_{2}}{\partial c_{3}} \frac{\partial c_{3}}{\partial r}\right)\right] .
\end{gathered}
$$

The length of working life $r_{G}^{*}$ the government chooses is longer than the length $r^{*}$ preferred by the individual as long as the utility from preserving the status quo $u_{R}\left(o_{i}\right)$ is positive.

\subsection{The individual's choice of the health signal $\hat{\theta}_{i}$}

An individual has an incentive to misrepresent his true expectation of being healthy in the second stage $\left(\hat{\theta}_{i} \neq \theta_{i}\right)$ if a lower signaled probability of being healthy induces the government to choose a shorter length of working life in the third stage. This is 
the case whenever the fraction of healthy individuals in the society is low or when the effect of a change in the length of working life has a strong effect on the attainable consumption level during retirement. ${ }^{3}$

If there is a difference between stated and true expectations, the difference will be determined by the two optimality conditions, that is to say, by the difference between equation (7) and equation (8). This difference amounts to

$$
\hat{\theta}_{i}^{*}=\theta_{i}^{*}-\frac{u_{R}\left(o_{i}\right)}{u_{1}\left(c_{1}\right)-u_{1}\left(c_{2}\right)+r\left(\frac{\partial u_{1}}{\partial c_{1}} \frac{\partial c_{1}}{\partial r}-\frac{\partial u_{1}}{\partial c_{2}} \frac{\partial c_{2}}{\partial r}\right)} .
$$

In equation 9, a number of factors determine the bias in signaled health expectations: First, it increases in the individual utility attached to maintaining the status quo $u_{R}\left(o_{i}\right)$. Second, it decreases with a decrease in the difference between the utility when working and healthy and the utility when not working and healthy $\left(u_{1}\left(c_{1}\right)-u_{1}\left(c_{2}\right)\right)$. Third, it is affected by the trade-off between the length of working life $r$ and its effect on consumption possibilities during working life $\left(\frac{\partial u_{1}}{\partial c_{1}} \frac{\partial c_{1}}{\partial r}-\frac{\partial u_{1}}{\partial c_{2}} \frac{\partial c_{2}}{\partial r}\right)$.

Work ability expectations depend on a number of well-known individual health and other risk factors (see Tuomi et al. 2001, for example) as well as on individual socio-demographic and economic characteristics (see, e.g. Adams et al. 2003; Munnell et al. 2008). Importantly, our model implies that - unless consumption possibilities were very similar when healthy and unhealthy, which they are not under a uniform proportional tax rate - a bias in stated health expectations should always remain.

\footnotetext{
${ }^{3}$ It can also be shown that the government has the possibility to affect the extent of the bias in the signal by setting the tax rate $\tau$ in the first stage. The presentation of the first stage decision is omitted here. Intuitively, while the relation between working life consumption when healthy and when unhealthy is fixed in the model, the only way to correct for the bias is the effect of the length of working life on retirement benefits via the tax rate. The government however faces a trade-off between consumption smoothing and correcting for the bias.
} 


\section{Design and implementation of the survey experiment}

The empirical analysis presented in the remainder of the paper focuses on investigating whether the bias we illustrated in the theoretical model in the previous section distorts the health signal the government obtains from questions typically asked in surveys or opinion polls. We thus ask: Is there evidence that stated individual expectations of work ability are affected not only by underlying health, risk and socio-demographic factors, but also by unobservable fundamental opposition? To isolate such an effect, we experimentally manipulate the effect fundamental opposition can have on responses.

We ask a question on work ability expectations for different target ages, but only one of the experimental conditions is associated with a change in status quo (i.e., a change in $r$ ). In order to control for any other effects which might drive opposition to pension reforms, we need detailed information on individual health, risk factors, and the respondents' socio-demographic characteristics, including their pension claims. We achieve this by embedding our experiment into a large panel survey which had already collected all this information. Our analysis can thus attribute any remaining variation in stated work ability expectations to fundamental opposition.

This section describes the German SAVE survey in which the experiment was embedded and our experimental design.

\subsection{The SAVE survey}

Our goal is to identify potential fundamental opposition in stated work ability expectations. We make use of the fact that the determinants of true work ability, such as health and risk factors, are both well-known in the literature and measured in our survey. We use the determinants of work ability as proxies for true work ability expectations. Our econometric model, as explained below in detail, thus includes the determinants of work ability, such as detailed information on health expectations, domain-specific measures of risk, and a measure for time preference as controls. Furthermore, we must also control for institutional features of the pension system, in particular the implicit 
tax on continued work, and for individual savings behavior. In order to do so, we also include savings measures and an estimate of accrued pension claims in our model, in addition to the usual socio-demographic variables. Finally, to proxy the underlying true work ability, we include its observable determinants: detailed individual health measures, current age, and satisfaction with work (see, e.g., Tuomi et al. 1997).

The German SAVE survey, a representative panel study which the University of Mannheim conducts in collaboration with TNS Infratest, is specifically designed to study retirement and savings behavior of German households. The survey started in 2001 and has been repeated annually since 2003. It records detailed information on financial variables (such as income, savings, and asset holdings), socio-demographic and psychological characteristics (such as job characteristics, preferences and expectations), and health status of the respondents. The data universe for the SAVE survey is all German language households in Germany with a household head of eighteen or older. Interviewees were selected from a multiply stratified multistage random sample augmented with a small quota sample. Table A.2 in the appendix contains descriptive statistics on all variables we use in our analyses. Further details on the data background as well as methodological information on the SAVE survey are presented in section A.2 of the appendix.

For this paper, we use data from the 2006 wave of the German SAVE panel study (which contained our survey experiment) appended with data from the 2007 wave for certain specifications.

\subsection{The experiment}

We included a controlled experiment in the 2006 wave of the SAVE survey. The complete survey was identical for all respondents, except for the experimental question on work ability. There were three different versions to this question, and respondents were randomly assigned to answer one of them. A question on (expected) work ability was asked for the first time in SAVE 2006. Therefore, the experimental nature is also ensured for those respondents who were members of the panel in previous years. 
Furthermore, our experimental question was the last question on the questionnaire, thus preventing repercussions on answers to any other question asked in the survey, such as the question on expected retirement age or any of the large battery of questions on individual health.

Our experiment in the SAVE survey was conducted in the year before both houses of the German parliament finally passed the reform which raised the statutory retirement age. At the time of our experiment, the German parliament discussed raising of the statutory retirement age from 65 to 67 , and this discussion was prominent in the media. Thus, individual opinions concerning the plans to increase the retirement age are likely to bias work ability expectations. By starting the experimental question with reference to the corresponding political context, we ensured that each respondent was in the same frame when answering the question. In other words, if the framing of the question resulted in biased responses, the bias would be identical for all respondents. The wording of the question was as follows:

To conclude this survey, we would like to ask you a question on current pension politics.

Please only answer the question if you are not older than 60.

Certainly you have already heard of the Grand Coalition's plans to gradually raise the statutory retirement age in order to avoid further curtailing of pensions. Do you think that you would be able to cope with your job's requirements at the age of $X$ ?

0

$\uparrow$

Not at all
10

$\uparrow$

Definitely

In Germany, the average retirement age among pensioners is currently about 60 years (e.g, for the cohort born in 1941 it is 60.6 years). Average retirement age is only slightly higher if disabled retirees are excluded. Therefore, only respondents up to age 60 were asked the experimental question. ${ }^{4}$ These respondents were randomly divided

\footnotetext{
${ }^{4}$ In the empirical analysis presented in this paper, we also exclude respondents who were already retired at an age below 60 as well as the self-employed and civil servants; for details, see appendix A.2.
} 
into three groups of equal size associated with one value of the variable $X$ from the set $(63,65$, and 67$)$. Respondents were asked to rate their expected work ability at age $X$ on a scale from 1 to 10 . As the statutory retirement age in Germany was 65 at the time of the experiment, one group was asked to rate their expected future work ability at that age. The second group was asked for their expected work ability at 63 , and the third group for their expected work ability at the age of 67 , the age to which the statutory retirement age should be raised according to the reform plans.

Comparing these three randomly assigned groups, which only differ with respect to the age at which they are asked to rate their expected work ability, is informative with respect to two issues. First, the experiment is a between-subjects design informing us whether work ability expectations truly decrease in a random sample of the population: if respondents expect their work ability to decrease with age, average work ability should be lower in the 67 group than in the 65 group and lower in the 65 group than in the 63 group. That is to say, we would observe a monotone decrease in work ability. Second, we learn about the potential bias due to fundamental opposition to a reform, which raises the retirement age to 67: If fundamental opposition plays a significant role, we should expect the 67 group to behave fundamentally different from the expected monotone decrease.

Our experimental design and the large coronary of additional data thus enable us to link the variation in stated work ability expectations, which cannot be related to underlying risk factors, to fundamental opposition.

\section{Results}

In this section, we present the empirical analysis of the data from our survey experiment. Our results show that expected work ability stated by West German survey respondents varies with known risk factors. Fundamental opposition to reforms causes bias in the responses from East German participants, however. These results are representative for the German population aged 18 to 59 (excluding the self employed and civil servants, as these groups are not covered by the statutory pay-as-you-go pension 
system). We provide a detailed discussion of our sample as well as descriptive statistics in appendix A.2.

Our analysis proceeds in several steps. We begin by comparing the responses to our main survey question between treatment groups in order to illustrate the effect of the experimental manipulation. We then estimate multivariate regression models that control for the determinants of individual retirement choices. We include three types of variables. First, we control for variables that determine the individual retirement choice (demographic characteristics, savings, wealth, and pension claims as well as data on risk and time preferences). Second, we control for known determinants of future work ability (in particular various subjective and objective health measures). Finally, we augment our survey data with administrative data on social security pensions to capture incentives provided by the German pension system. Throughout, we also investigate potential differences between respondents in East and West Germany.

\subsection{Expected work ability at 63,65 , and 67}

We first report descriptive statistics on the responses to the experimental question. Table 1 displays mean and median work ability for the three experimental groups, separately for East and West Germany. Pooling data from all three treatment groups, we find that more than $70 \%$ of West German respondents and nearly $80 \%$ of East German respondents rate their expected work ability around retirement as low (equal to or lower than 5 on an eleven-point scale). Moreover, median work ability is only 3 and 2 on the eleven-point scale in West and East Germany, respectively.

In West Germany, mean and median work ability decrease monotonically with the experimental manipulation of the time horizon, as we hypothesized. Significant differences between the three experimental groups for median work ability, respectively, are confirmed by a Kruskal-Wallis test for the West German sample $(p<0.0001)$. Equality of population medians cannot be rejected for the East German sample, however $(p=0.2985)$. These results suggest that although opposition effects do not seem to 
bias responses in West Germany, they do seem to matter in the East. In the following, we proceed with a multivariate analysis that substantiates this claims.

[Table 1 about here]

\subsection{Multivariate analysis}

The dependent variable in our multivariate analysis is expected work ability at retirement age. Our regressions can be interpreted as reduced-form specifications of equation (9) which we derived from our theoretical model. Since expected work ability was measured on an eleven-point scale in the survey, we use an ordered probit model in which the observed ordered response is determined by unobserved (latent) expected work ability, which in turn is specified as a linear index that combines a large number of explanatory variables:

$$
\hat{\theta}_{i}^{*}=\mathbf{x}_{\mathbf{i}} \boldsymbol{\beta}_{\boldsymbol{x}}+\mathbf{p}_{\mathbf{i}} \boldsymbol{\beta}_{\boldsymbol{p}}-\mathbf{q}_{\mathbf{j}} \boldsymbol{\beta}_{\boldsymbol{q}}+u_{i}
$$

Here, the vector $\mathbf{x}_{\mathbf{i}}$ collects determinants of true work ability expectations $\theta_{i}^{*}, \mathbf{p}_{\mathbf{i}}$ includes additional variables which might affect the incentive to deflate stated work ability expectations, and $\mathbf{q}_{\mathbf{j}}$ denotes the questionnaire indicators with $j \in(63,65,67)$. That is to say, $\mathbf{p}_{\mathbf{i}}$ should include any individual (future) consumption levels, such as income and savings, as well as demographic indicators and whether someone is affected by the reform. The unknown parameter vectors are denoted by $\boldsymbol{\beta}_{\boldsymbol{q}}, \boldsymbol{\beta}_{\boldsymbol{x}}$, and $\boldsymbol{\beta}_{\boldsymbol{p}}$, respectively. We assume that the error term, $u_{i}$, is normally distributed and statistically independent of the regressors, which gives rise to an ordered probit model that we estimate by maximum likelihood.

First, we estimate a model specification which includes demographic indicators as well as financial and institutional controls. Our second specification further includes health, health expectations, and job details. We finally add social security data to control for differences in respondents' public pension accounts in our third specification. The results are displayed in table 2 and table 3, for West Germany and East Germany, respectively. 
[Table 2 about here]

[Table 3 about here]

Our main result is already highlighted by comparing specification (1) in tables 2 and 3. This specification includes demographic indicators, income and wealth variables. Demographic indicators in particular can capture political preferences, which may lead to the repulsion of the reform; thus our estimation controls for opposition to the reform that is related to respondent characteristics. ${ }^{5}$ We find that both indicator variables for the questionnaires are significant and have the hypothesized sign in the West German sample, suggesting a monotone decrease in expected work ability with age. However, work ability is significantly higher in the 63 group and in the 67 group in East Germany - a pattern which contradicts the hypothesis that respondents have reported expectations that are meaningful given their actual life situation. ${ }^{6}$ Hence, while opposition effects do not seem to bias responses in West Germany, they do seem to matter in the East. Note that our estimations above also include information on various sources of old-age income. This even includes wealth in private pension schemes. Most of these variables are highly significant in both parts of the country. Still, there is no indication of fundamental opposition in the West, while the opposition

\footnotetext{
${ }^{5}$ In appendix section A.3 we show that demographic characteristics can indeed explain a large fraction of opposition against the reform in opinion poll data. In addition, specification (1) contains an indicator variable of being affected by the reform and an indicator variable for respondents who experienced German reunification as adults.

${ }^{6}$ We should mention that the observed pattern does not only contradict the initial hypothesis in the sense of not finding support for a monotone decrease in expectations, but that health expectations seem to be even higher at 67 than at 65 in East Germany. Further analysis suggests that this increase in expectations is driven by a specific group of respondents in the East: Respondents who - due to the poor employment situation there - have experienced strong income fluctuations in the past, are thus very uncertain about their future work situation, expect an inadequate retirement income, and might therefore anyhow anticipate that they will have to work beyond the usual retirement age in any case. Moreover, if we fully interact the models estimated in tables 2 and 3 with an indicator variable for large income fluctuations in the past 5 years, we find that the dummies for the treatments 63 and 67 become insignificant and low in magnitude in the East sample but not in the West sample - another indication of an opposition effect in the East.
} 
effect in the East remains.

While the reaction to our experiment among West German respondents seems to confirm that West Germans expect their work ability to decrease with age, we still have to show that this corresponds to true expectations. This is what we do in specification (2). We approximate true expectations by including the determinants of work ability as explanatory variables, which have been proven to be the most important determinants of work ability in previous research. Specifically, we include several measures of subjective health, health expectations, and objective health measures. In addition, previous research suggests that life style - including smoking habits or the type of work, in particular if it is physically demanding - and job satisfaction play a great role (e.g., Tuomi et al. 1997). We thus also include these measures as well as domain-specific measures of risk. Specification (2) in tables 2 and 3 displays our results including these determinants of work ability.

Several work, health and life style variables significantly affect answers in both East Germany and West Germany. The most important determinants of work ability, however, show the expected effect in West Germany, but not in East Germany. For instance, both smokers and respondents working in a physically demanding job have significantly lower work ability expectations in the West, but not in the East. We conclude that stated work ability expectations indeed contain information about true expectations, because all underlying risk factors correlate with stated expectations in a reasonable way. A pooled model with full interactions for East-West differences however reveals that the general picture of stated expectations being driven by individual risk factors does not apply to East German respondents. Stated expectations are thus likely to be biased by fundamental opposition among East German respondents (see also section 4.3 for further details).

\subsection{Sensitivity of the results}

In Germany, the level of the pension claim depends on the amount of lifetime contribution payments. These strongly depend on income. So far, we have argued that 
income effects on the retirement decision are best captured by including data on current income ${ }^{7}$ and measures of risk aversion. In addition, we also used demographic indicators and economic expectations, which have proven to be strong determinants of whether someone supports the reform in the regression analysis using opinion poll data (shown in appendix section A.3). We also controlled for numerous individual risk factors, such as health conditions. In the specification presented in this section, we additionally control for incentives provided by the German pension system. For instance, insufficient pension claims could possibly have caused our observation in specifications (1) and (2) of table 3 that East Germans even seem to expect to be more able to work at the age of 67 than at 65 .

We augment our data with German social security data (Forschungsdatenzentrum der deutschen Rentenversicherung 2008), in particular with measures of individual pension entitlements. The German social security data set we use consists of a $1 \%$ random sample (385,503 observations) of all Germans contributing to the public pension system in 2005. For all individuals in the sample, we know exactly the number of pension credits (Entgeltpunkte) accumulated in 2004 and by 2005, for which spell of employment these credits were accrued, and for how many months the person was unemployed in the respective year. We also know the year of first contribution to the system and non-contribution times that were recognized as contribution times. ${ }^{8}$ We match these numbers to each respondent in our main data set conditional on a set of socio-demographic variables (federal state of residence, gender, age, and type of job). ${ }^{9}$

Specification (3) in tables 2 and 3 shows the results of specifications that include variables such as employment biography and contributions to the system. None of the coefficients we are interested in change much, and we still observe a monotone decline

\footnotetext{
${ }^{7}$ Note that our data also allow us to identify precisely those who work in a job that is not covered by social security.

${ }^{8}$ This refers, for example, to the first weeks of maternity leave or unemployment, when an employee does not have to actively contribute to the system. The employer does so for him or her, in accordance with German legal provisions.

${ }^{9}$ We lose one observation of our original data set in this process. This is due to age restrictions.
} 
in work ability expectations with age for the West German sample, but not for the East German sample. Focusing on the newly included variables in specification (3), we find that a later year of first contribution (i.e., a shorter total time span for contributing to the system) has a negative effect in East Germany, but the effect is positive in West Germany. Furthermore, accrued pension credits in 2005 and 2004 as well as spells of non-contribution times do not have a significant influence (not displayed in the tables). In contrast, non-contribution times have a weak but significantly positive effect in Eastern Germany. ${ }^{10}$ More importantly, the accrued pension credits are not significant in either part of the country. We are thus confident that our strategy of including detailed information on income and savings has indeed captured the most important incentive effects of the pension system which may cause differences in the preferred retirement age.

To make sure that the persistent differences in the reaction between East and West German responses in our data are not caused by differences in other variables either, we show that the characteristics of East and West German respondents do not differ significantly in a detailed comparison of the samples in appendix section A.2. We also estimate a fully interacted model of East-West differences, the results of which are displayed in specification (1) in table 4 . While there is no difference between the higher level of work ability in the 63 group as compared to the 65 group between East and West Germany, there is a significant difference between the East and West German sample for the 67 group. This confirms the results of tables 2 and 3 .

In our multivariate analysis we have ruled out health as the cause of East-West differences by including subjective and objective health measures. It could be, however, that the differences are caused by unobserved differences in work ability. To see whether this is plausible, we also ran the fully interacted specification including the self-employed and public officials, who are unaffected by the reform. Results for selected variables are displayed in specification (2) in table 4. All findings with re-

\footnotetext{
${ }^{10}$ This effect is related to the fact that the unemployment rate in the East is very high; more information can be obtained from the authors upon request.
} 
spect to the reaction to our experiment remain unchanged, lending support to our interpretation that fundamental opposition plays a role for respondents from Eastern Germany.

[Table 4 about here]

A final concern that we need to address is that the health variables included in our regressions are self-reported and thus potentially subject to differential bias. We thus also investigate health differences between East and West based on an established objective measure of health, namely maximum hand grip strength (e.g., Kuh et al., 2005). Our analysis uses data from the Survey of Health, Ageing and Retirement (SHARE), and it is presented in the appendix, section A.4. Maximum grip strength varies with gender and age, but not between East and West Germany. We are therefore confident that variations in health status do not drive differences between East and West Germans in our analysis.

\subsection{A note on communism and preferences}

Recent research has argued that Communism significantly shaped people's attitudes, beliefs and behavior in a significant manner (e.g., Alesina and Fuchs-Schündeln 2007; Ockenfels and Weimann 1999). Our data basically confirm this view. In particular, a variable indicating childhood and adolescence spent under communism, is significant in East Germany in specification (4) in table 3.

We should stress that this result is not due to the large and persistent differences in unemployment rates between East and West Germany. We control for regional unemployment rates, individual unemployment, and past unemployment in 2004 and 2005, in all regressions. Moreover, we also control for the impact of unemployment on pension entitlements in our multivariate regressions. 


\section{Conclusions}

Persistent opposition to pension reforms is a widespread phenomenon in many countries that struggle to maintain the sustainability of their pay-as-you-go pension system. As a consequence, policy-makers facing reelection are confronted with incentives to avert pension reforms. It is not clear, however, to what extent the persistent opposition against pension reforms expressed in opinion polls reflects the electorate's underlying preferences and expectations, or rather mirrors fundamental opposition to reforms. If the latter were the case, the implementation of reforms could be welfare-enhancing even if polls clearly suggest the contrary. It is thus of fundamental interest to learn more about the extent to which simple opinion poll questions reflect factors other than underlying preferences and expectations related to a specific reform proposal.

To investigate whether fundamental opposition to pension reforms really is an issue, we study whether the arguments that people put forward against a specific reform proposal are reasonable given their life situation. We use an experiment embedded in a representative survey and investigate a prominent argument against raising the retirement age: people's fear of low work ability as they approach the retirement age. Specifically, we use the context of a German pension reform, which was implemented in 2007 and raised the statutory retirement age from 65 to 67 .

Our data convey three main results. First, the main concern in the public discussion - that people become increasingly unable to work beyond the age of 65 - is clearly reflected in individual expectations. Second, we find no evidence for an additional downward bias in stated work ability expectations due to fundamental opposition in West Germany. This suggests that opposition in West Germany is only caused by the concern of becoming less able to work with increasing age and not by fundamental opposition. Third, our experimental design reveals that there is additional variation in expected work ability in East Germany, which cannot be linked to underlying risk factors and health expectations and which we interpret as evidence for fundamental opposition. 
Our results offer two important insights. First, our experiment reveals persistent differences between East and West Germany that cannot be linked to differences in risk factors or the life situation. This challenges an important assumption of many policy-makers, namely that acting according to the opinions expressed in representative polls always is in the best interest of a society's welfare. Our analysis underlines the urgency of addressing discontentment with politics and the welfare state in the former communist Eastern part of Germany.

Second, our data suggest that simple rating questions can provide valuable information in the sense that responses reflect people's underlying life situation and their concerns and expectations. Specifically, with the help of our experimental manipulation, we find that expected work ability decreases substantially between age 63 and 67 , suggesting that the fear of being unable to work is a serious concern among the electorate.

At the same time, recent research shows that people live longer (Oeppen and Vaupel 2002), that the incidence of old-age disability decreases (e. g. Manton and Gu, 2001), and that neither health-related absence nor productivity decrease with age (Börsch-Supan and Weiss 2008). Hence there seems to be a growing consensus among researchers that it is not only necessary to increase the retirement age, but that workers in many occupations can be productive beyond the current retirement age. Boosting acceptance of such a reform thus requires policy-makers to increase awareness of the fact that life expectancy is rising, that people stay healthier at older ages than ever before, and that they do not rapidly lose their productivity in many jobs even beyond age 60. As long as voters are not informed about their health prospects and the effects that ageing may or may not have on their work ability, they are unlikely to endorse reforms that would raise the retirement age. Since work ability and health expectations are a good predictor of actual retirement behavior (e. g. McGarry 2004), policy-makers must address people's concerns about low work ability expectations more fervently if they wish policy reforms that raise the statutory retirement age and enhance the sustainability of the pension system to be ultimately successful. 


\section{References}

[1] Adams, Peter, Michael Hurd, Daniel McFadden, Angela Merrill, and Tiago Ribeiro, 2003, Healthy, Wealthy, and Wise? Tests for Direct Causal Paths between Health and Socioeconomic Status, Journal of Econometrics, Vol. 112, 3 56.

[2] Alesina, Alberto, and Nicola Fuchs-Schündeln, 2007: Good Bye Lenin (Or Not?): The Effect of Communism on People's Preferences, American Economic Review, Vol. 97, $1507-1528$.

[3] Benítez-Silva, Hugo, Debra S. Dwyer, Wayne-Roy Gayle, and Thomas J. Muench, 2008: Expectations in micro data: rationality revisited, Empirical Economics, Vol. $34,381-416$.

[4] Bertrand, Marianne, and Sendhil Mullainathan, 2001: Do People Mean What They Say? Implications for Subjective Survey Data, American Economic Review, Vol.91, No.2, Papers and Proceedings of the Hundred and Thirteenth Annual Meeting of the American Economic Association, 67 - 72.

[5] Boeri, Tito, Axel Börsch-Supan, and Guido Tabellini, 2002: Pension Reforms and the Opinions of European Citizens, American Economic Review, Vol. 92, No. 2, Papers and Proceedings of the One Hundred Fourteenth Annual Meeting of the American Economic Association, 396 - 401.

[6] Boeri, Tito, and Guido Tabellini, 2008: Does information increase political support for pension reform?, Working Paper.

[7] Börsch-Supan, Axel, 2003: Labor Market Effects of Population Aging, Review of Labour Economics and Industrial Relations, Vol. 17, Special Issue 2003, 5 - 44.

[8] Börsch-Supan, Axel, 2004: Mind the Gap: The Effectiveness of Incentives to Boost Retirement Saving in Europe, MEA Discussion Paper, No. 52-2004.

[9] Börsch-Supan, Axel, Florian Heiss, and Joachim Winter, 2004: Akzeptanzprobleme bei Rentenreformen, Deutsches Institut für Altersvorsorge: Köln. 
[10] Börsch-Supan, Axel, and Matthias Weiss, 2008: Productivity and the Age Composition of Work Teams: Evidence from the Assembly Line, MEA Discussion Paper, No. 148-07.

[11] Börsch-Supan, Axel, Michela Coppola, Lothar Essig, Angelika Eymann, and Daniel Schunk, 2008: The German SAVE Study. Design and Results, mea Studies 06, Mannheim Research Institute for the Economics of Ageing (MEA): Mannheim.

[12] Bütler, Monika, 2000: The political feasibility of pension reform options: the case of Switzerland, Journal of Public Economics, Vol. 75, 389 - 416.

[13] Bütler, Monika, 2002: The Political Feasibility of Increasing the Retirement Age: Lessons from a Ballot on the Female Retirement Age, International Tax and Public Finance, Vol. 9, 349 - 365 .

[14] Burtless, Gary, and Joseph Quinn, 2000: Retirement Trends and Policies to Encourage Work among Older Americans, in: P.P. Budetti, R.V. Burkhauser, J.M. Gregory, and H.A. Hunt (eds.), Ensuring Health and Income Security for an Aging Workforce, Upjohn Institute for Employment Research: Kalamazoo.

[15] Cukierman, Alex, 1991: Asymmetric information and the electoral momentum of public opinion polls, Public Choice, Vol. 70, 181 - 213.

[16] Diamond, Peter A., and James A. Mirrlees, 1978: A model of social insurance with variable retirement, Journal of Public Economics, Vol. 10, 295 - 336.

[17] Forschungsdatenzentrum der Deutschen Rentenversicherung, 2008: SUF Aktiv Versicherte im Berichtsjahr 2005.

[18] Forschungsgruppe Wahlen, 2007: Politbarometer West und Ost 2005, Zentralarchiv für empirische Sozialforschung an der Universität zu Köln.

[19] Kuh, Diana, E. Joan Bassey, Suzanne Butterworth, Rebecca Hardy, Michael E. J. Wadsworth and the Musculoskeletal Study Team, 2005: Grip Strength, Postural Control, and Functional Leg Power in a Representative Cohort of British Men and 
Women: Associations With Physical Activity, Health Status, and Socioeconomic Conditions. The Journals of Gerontology Series A: Biological Sciences and Medical Sciences, Vol. 60, $224-231$.

[20] Manski, Charles F., 2004: Measuring Expectations, Econometrica, Vol. 72, 1329 $-1376$.

[21] Manton, Kenneth G. and XiLiang Gu, 2001: Changes in the prevalence of chronic disability in the United States black and nonblack population above age 65 from 1982 to 1999, Proceedings of the National Academy of Sciences, Vol.98, No. 11, 6354-6359.

[22] McGarry, Kathleen, 2004: Health and Retirement Do Changes in Health Affect Retirement Expectations?, Journal of Human Resources, Vol. 39, $624-648$.

[23] Morwitz, Vicki, and Carol Pluzinski, 1996: Do Polls Reflect Opinions or Do Opinions reflect Polls? The Impact of Political Polling on Voters' Expectations, Preferences, and Behavior, Journal of Consumer Research, Vol. 23, 53 - 67.

[24] Munnell, Alicia H., Mauricio Soto, and Alex Golub-Sass, 2008: Will People be Healthy Enough to Work Longer?, Center for Retirement Research Working Paper No. 2008-11.

[25] Ockenfels, Axel, and Joachim Weimann, 1999: Types and patterns: an experimental East-West-German comparison of cooperation and solidarity, Journal of Public Economics, Vol. 71, No. 2, 275 - 287.

[26] O'Donnell, Owen, Federica Teppa, and Eddy van Doorslaer, 2008: Can Subjective Survival Expectations explain Retirement Behaviour, DNB Working Paper, No. 188.

[27] Oeppen, Jim, and James W. Vaupel, 2002: Broken Limits to Life Expectancy, Science, Vol. 296, No. 5570, 1029 - 1031.

[28] Page, Benjamin, and Robert Shapiro, 1984: Effects of Public Opinion on Policy, American Political Science Review, Vol. 77, No. 1, 175 - 190. 
[29] Schunk, Daniel, 2008: A Markov Chain Monte Carlo algorithm for multiple imputation in large surveys, Advances in Statistical Analysis, Vol. 92, 101 - 114.

[30] Tuomi, Kaija , P. Huuhtanen, E. Nykyri, and Juhani Ilmarinen, 2001: Promotion of work ability, the quality of work and retirement, Occupational Medicine, Vol. 51, No. $5,318-324$.

[31] Tuomi, Kaija, Juhani Ilmarinen, Matti Klockars, Clas-Håkan Nygård, Jorma Seitsamo, Pekka Huuhtanen, Rami Martikainen, and Lea Aalto, 1997: Finnish research project on ageing workers in 1981-1992, Scandinavian Journal of Work, Environment, and Health, Vol. 23, Supplement 1, 7 - 11. 


\section{Appendix}

\section{A.1 Institutional rules for public old-age pensions in German}

The increase in the retirement age was one of the last steps of the tentative implementation of the suggestions by the Rürup-Kommission, which was the scientific advisory council to the Government and which presented suggestions on how to reform the German Public PAYG pension system in 1999. Some of these suggestions were implemented under Chancellor Gerhard Schröder, who was in office between 2002 and 2004. The increase in the statutory retirement age was, however, only reintroduced by the Grand Coalition under Chancellor Angela Merkel, with a long transition period (2012 - 2029). It was passed in both houses of parliament in March 2007. Reform details are presented in table A.1.

\section{A.2 The SAVE survey and sample definition}

The SAVE study: The SAVE household panel survey was started in 2001 with the aim of gaining a more thorough understanding of the savings and retirement behavior of German private households. It has emerged as a cooperation project of researchers from the University of Mannheim, the Mannheim Center for Surveys, Methods and Analyses (ZUMA), NFO Infratest (Munich), Psychonomics (Cologne) and Sinus (Heidelberg). The survey design was based on the Dutch CentER panel and the U.S. Health and Retirement Study (HRS). To our knowledge, the German SAVE panel is currently the only panel study which combines a large set of micro data with rich and particularly detailed information on household saving and its determinants. This is of vital importance for our study, since we not only control for the financial determinants of retirement behavior, such as both private and public saving flows for old age, but also for health, health expectations, risk and time preferences, and a huge set of socio-demographic variables. Combined with further information about relevant individual level determinants of retirement behavior, such as expected old age provision, general economic expectations, job satisfaction, life-style etc., the SAVE data offer a unique possibility to gain a detailed picture of the factors that can influence a 
household's retirement decision. Details on the SAVE data, on the sampling scheme, item non-response, imputation procedures, weighting, and data quality can be found in Börsch-Supan et al. (2008). Here, we provide only a brief summary.

Item nonresponse, imputation, and weighting: Item nonresponse in SAVE mainly occurs with sensitive questions on the respondent's financial situation; item nonresponse rates are similar to item nonresponse rates in other surveys (see BörschSupan et al., 2008). To prevent biased inference based on an analysis of only complete cases, a Markov chain Monte Carlo imputation procedure was applied to the SAVE data (see Schunk, 2008). The imputation procedure explicitly takes the available information in all different waves into account, thus ensuring maximum data quality. The method replaces missing data by drawing from an estimate of the conditional distribution of the data, and the Markov chain Monte Carlo process converges robustly in only few iteration steps. We also conducted all our analyses with the sample of non-imputed data only, but results are hardly affected. More information on this is found in the next section. Socio-demographic representativeness of the SAVE panel is ensured by a weighting scheme according to the German Micro Census (Mikrozensus).

Sample definition: The sample for our analyses consists of individuals at working age who are affected by the pension reform. As the self-employed are not covered by the public PAYG pension system we exclude them from our analysis. A similar reasoning applies to respondents who are employed in public service. Although they are covered by a PAYG pension scheme, this is administered differently and in a slightly more generous way compared to the standard scheme. We thus exclude this group from our analysis as well. In order to account for remaining differences with respect to the type of job, all our analyses control for both physical fitness and physically demanding tasks, as well as for the type of job. We restrict the remaining sample to individuals aged 59 or younger, because the effective retirement age in Germany is clearly below the statutory retirement age of 65 . We also exclude respondents, who are already retired or are in early retirement due to disability from our sample. Out of the original data set of 3,474 observations in the 2006 wave, 1,852 remain in our sample. Table 
A.2 shows the number of respondents in each group in East and West Germany.

Summary statistics and differences between East and West Germany: Apart from differences in unemployment, the East and West German samples do not differ with respect to key characteristics. In particular, it is also important to note that the East and West samples do not differ significantly with respect to job type, an important determinant of work ability expectations. Table A.2 shows that the main differences between our East and West German samples can indeed be related to the much higher unemployment rate in the East. The unemployment rate in East Germany is almost $24 \%$ in the sample. This is slightly higher than the official figure $20.6 \%$ for 2005 . The proportion of respondents who experienced strong income fluctuations during the past 5 years is also higher in the East, which can be related to difficulties in finding gainful employment. This is in line with the average household income per household member, which is higher in West Germany. Not surprisingly, West Germans are somewhat more satisfied with work, expect a better individual economic situation and better health in the future, and expect to live slightly longer than East Germans. ${ }^{11}$

\section{A.3 Attitudes towards reforms in the Politbarometer}

Another potential candidate for explaining the difference between East and West Germany might be a general opposition to reforms of the welfare state in the East which is caused by a higher preference for redistribution in the former Communist part of Germany, or by differences in opportunities in life caused by the difficult employment situation in the East. We use data from German opinion polls on the pension reform to check for the main determinants of individual opposition. Summary statistics for the opinion poll data are displayed in table A.3.

\footnotetext{
${ }^{11}$ The variable life expectancy is measured in a complicated procedure consisting of three different survey questions. Respondents are asked, first, how they estimate the average life expectancy of their cohort for both genders separately. Second, they are asked whether they expect to live just as long, longer, or shorter than their cohort. In a third step, respondents are asked to estimate the number of years which they expect to live longer or shorter.
} 
Table A.4 shows a probit analysis of the probability of supporting the reform which raised the statutory retirement age to 67 . This analysis is based on the representative opinion poll data from the Politbarometer. The analysis clearly reveals that East German respondents are ceteris paribus less likely to support the reform. It further shows that supporting the reform is mainly determined by indicators which are related to how many pension credits someone has already accumulated and also to their potential for accruing a higher pension if they continue working. In particular, gender, education, and employment play a large role. Unfortunately, the opinion polls do not ask for information on income, which is why we could not include this information in our analysis. Overall, table A.4 gives important insights as to which variables are related to a negative attitude towards the reform. In particular, this confirms that many control variables we use for identification of a fundamental bias from between-groups variation in our SAVE survey experiment are crucial for identifying a fundamental opposition effect.

\section{A.4 Objective health differences between East and West Germany}

As we have shown, the SAVE data suggest that there are no differences in health status between East and West Germans. The SAVE data, however, contain subjective, self-rated health measures. Objective health data, which does not involve a subjective rating, may convey a different picture. Thus, we additionally check whether an established objective measure of health, hand grip strength, differs significantly between East and West Germany. Grip strength was measured in a representative sample of Germans aged 50 and above in the context of the the Survey of Health, Ageing and Retirement in Europe (SHARE), a multidisciplinary and cross-national panel database of micro data on health, socioeconomic status and social and family networks. ${ }^{12}$

\footnotetext{
${ }^{12}$ We used data from SHARE Waves 1 and 2, as of December 2008. In 2004-2007, SHARE data collection was primarily funded by the European Commission through its 5 th and 6th framework programmes (project numbers QLK6-CT-2001- 00360; RII-CT- 2006-062193; CIT5-CT-2005-028857). Additional funding by the US National Institute on Aging (grant numbers U01 AG09740-13S2; P01 AG005842; P01 AG08291; P30 AG12815; Y1-AG-4553-01; OGHA 04-064; R21 AG025169) as well as
} 
We do not find that our objective measure of health differs between East and West Germans. Figure A.1 shows that this objective measure of health declines with age and that there are differences between men and women, but there are no differences between East and West Germans within these groups. This result is confirmed in a regression analysis which is available from the authors upon request.

by various national sources is gratefully acknowledged. 


\section{Tables and figures}

Figure 1: Fraction opposing an increase of the retirement age

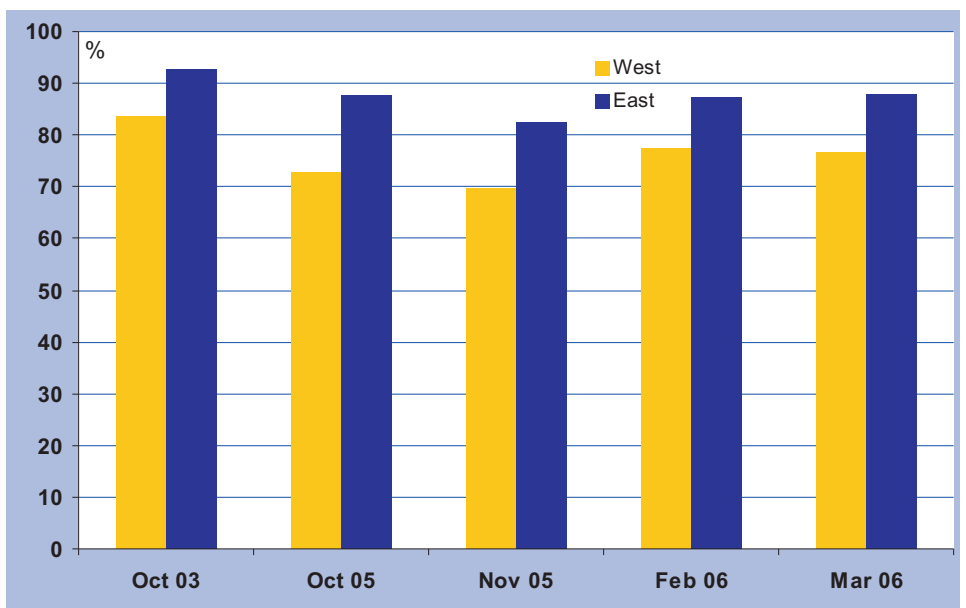

Source (data): Forschungsgruppe Wahlen (2007)

Table 1: Expected work ability in the three experimental groups

\begin{tabular}{|c|c|c|c|c|c|c|c|c|}
\hline & \multicolumn{4}{|c|}{ West } & \multicolumn{4}{|c|}{ East } \\
\hline & Mean & Med. & Std. Dev. & Obs. & Mean & Med. & Std. Dev. & Obs. \\
\hline Exp. group 63 & 4.24 & 4 & 3.12 & 440 & 3.11 & 2 & 3.06 & 167 \\
\hline Exp. group 65 & 3.37 & 3 & 3.12 & 457 & 2.53 & 2 & 2.62 & 164 \\
\hline Exp. group 67 & 3.04 & 2 & 2.93 & 453 & 3.00 & 2 & 3.26 & 171 \\
\hline Obs. & & \multicolumn{2}{|c|}{1,350} & \multicolumn{5}{|c|}{502} \\
\hline
\end{tabular}


Table 2: Regression results - West Germany

(1) (2)

(3)

Dep. variable: expected future work ability

Questionnaire: 63 (D)

\begin{tabular}{|c|c|c|}
\hline .288 & .293 & .289 \\
\hline$(.071)^{* * *}$ & $(.071)^{* * *}$ & $(.071)^{* * *}$ \\
\hline-.131 & -.132 & -.136 \\
\hline$(.071)^{*}$ & $(.071)^{*}$ & $(.071)^{*}$ \\
\hline .091 & .103 & .106 \\
\hline$(.079)$ & $(.081)$ & $(.082)$ \\
\hline-.182 & -.164 & -.195 \\
\hline$(.161)$ & $(.161)$ & $(.178)$ \\
\hline-.202 & -.171 & -.171 \\
\hline$(.162)$ & $(.162)$ & $(.163)$ \\
\hline .368 & .220 & .226 \\
\hline$(.112)^{* * *}$ & $(.118)^{*}$ & $(.118)^{*}$ \\
\hline-.180 & -.230 & -.218 \\
\hline$(.084)^{* *}$ & $(.091)^{* *}$ & $(.091)^{* *}$ \\
\hline .014 & .003 & .005 \\
\hline$(.034)$ & $(.035)$ & $(.035)$ \\
\hline .011 & .025 & .020 \\
\hline$(.074)$ & $(.079)$ & $(.080)$ \\
\hline .086 & .077 & .078 \\
\hline \multirow[t]{7}{*}{$(.017)^{* * *}$} & $(.017)^{* * *}$ & $(.017)^{* * *}$ \\
\hline & .024 & .024 \\
\hline & $(.013)^{*}$ & $(.013)^{*}$ \\
\hline & -.195 & -.193 \\
\hline & $(.064)^{* * *}$ & $(.064)^{* * *}$ \\
\hline & .012 & .012 \\
\hline & $(.004)^{* * *}$ & $(.004)^{* * *}$ \\
\hline
\end{tabular}

Questionnaire: 67 (D)

Number of children

Age

Age: 18-40 in 1990 (D)

)

University degree (D)

Vocational degree (D)

HH income p.p. / 1000 (EUR)

Contrib. to $\mathrm{HH}$ inc. (\%)

Expectation: Germany's economy

Satisfaction with work

Exhausting act. in work or leisure (D)

Life expectancy (years)

Controls:

Demographic, financial and institutional

Job and health characteristics

Public pension account details

Health characteristics: Prob $>\mathrm{Chi}^{2}$

Obs.

\begin{tabular}{cccc} 
& YES & YES & YES \\
& NO & YES & YES \\
& NO & NO & YES \\
\hline$i^{2}$ & & 0.0002 & 0.0002 \\
\hline
\end{tabular}

Ordered probit regression of work ability expectations on different sets of controls. All variables from the respective categories of control variables shown in table A.2 are included, but most are not shown here. Data are taken from SAVE 2006 and SAVE 2007. For specification (3), we have additionally matched the survey data with official German social security data. Standard errors are reported in parentheses. Significance level: ${ }^{* * *}: p<0.001 ;^{* *}: p<0.05 ;^{*}: p<0.1$ 
Table 3: Regression results - East Germany

(1) (2)

(3)

Dep. variable: expected future work ability

Questionnaire: 63 (D)

.268

$(.117)^{* *}$

Questionnaire: 67 (D)

Number of children

Age

Age: $18-40$ in 1990 (D)

University degree (D)

Vocational degree (D)

HH income p.p. / 1000 (EUR)

Contrib. to $\mathrm{HH}$ inc. (\%)

Expectation: Germany's economy

Satisfaction with work

Exhausting act. in work or leisure (D)

Life expectancy (years)

Year of first contribution
.258

$(.120)^{* *}$

$-.098$

(.149)

$-.303$

(.280)

$-.471$

$(.250)^{*}$

.357

(.222)

$-.002$

(.193)

$-.107$

(.071)

$-.252$

$(.119)^{* *}$

.053

$(.029)^{*}$

)

\section{.}


Table 4: Sensitivity analysis - Fully interacted model

(1)

Dep. variable: expected future work ability

Questionnaire: 63 (D)

.290

$(.071)^{* * *}$

Questionnaire: $63 *$ East (D)

.013

(.143)

Questionnaire: 67 (D)

Questionnaire: $67^{*}$ East (D)

Number of children

Number of children * East

Age

Age * East

HH income p.p. / 1000 (EUR)

HH income p.p. / 1000 (EUR) * East

Exhausting act. in work or leisure (D)

Exhausting activities * East (D)

Year of first contribution

Year of first contr. * East

Controls:

Demographic, financial and institutional

Job and health characteristics

Public pension account details

Health characteristics: Prob $>\mathrm{Chi}^{2}$

Obs.
$-.135$

$(.071)^{*}$

.359

$(.143)^{* *}$

.106

(.081)

$-.269$

(.180)

$-.194$

(.178)

.002

(.337)

.004

(.035)

$-.160$

$(.085)^{*}$

$-.192$

$(.064)^{* * *}$

.103

(.126)

.023

$(.010)^{* *}$

$-.035$

$(.011)^{* * *}$
.282

$(.067)^{* * *}$

$-.012$

(.135)

$-.148$

$(.067)^{* *}$

.407

$(.135)^{* * *}$

.078

(.075)

$-.160$

(.167)

$-.174$

(.165)

$-.004$

(.319)

.027

(.032)

$-.136$

$(.077)^{*}$

$-.209$

$(.059)^{* * *}$

.124

.015

(.009)

$-.014$

(.014)

YES

YES

YES

0.0001

2,085

$\overline{\text { Ordered probit regression of work ability expectations on different sets of controls. All variables from table A.2 }}$ are included in the estimations, but most are not shown here. Data are taken from SAVE 2006 and SAVE 2007 and matched with information from German social security data. Standard errors are reported in parentheses. Significance level: ${ }^{* *}: p<0.001{ }^{* *}: p<0.05 ;^{*}: p<0.1$ 
Table A.1: Institutional background

\begin{tabular}{rl}
$\begin{array}{r}\text { Cohort } \\
\text { (year of birth) }\end{array}$ & Statutory Retirement Age \\
$1947-1957$ & $65+1$ month \\
& for all following cohorts raised by 1 additional month \\
1958 & $65+12$ months \\
$1959-1962$ & $65+14$ months \\
& for all following cohorts raised by 2 months \\
1963 & $65+22$ months \\
& 67 \\
$1964-$ present & cohorts 1954 and older, who agreed on partial retirement \\
& Exceptions \\
& claimants of benefits for unemployed mining workers \\
& (Anpassungsgeld für entlassene Arbeitnehmer des Bergbaus $)$ \\
\hline \hline
\end{tabular}

Source: Deutsche Rentenversicherung. 
Table A.2: Summary statistics

\begin{tabular}{|c|c|c|c|c|}
\hline \multirow[b]{2}{*}{ Variable } & \multicolumn{2}{|c|}{ West } & \multicolumn{2}{|r|}{ East } \\
\hline & Mean & Std. Dev & Mean & Std. Dev. \\
\hline \multicolumn{5}{|c|}{ Demographic, financial and institutional variables } \\
\hline No. of children & 0.677 & 0.468 & 0.753 & 0.432 \\
\hline Voc. degree (D) & 0.722 & & 0.749 & \\
\hline Univ. degree (D) & 0.135 & & 0.181 & \\
\hline HH income per person (EUR) & 990.66 & 831.38 & 785.71 & 665.45 \\
\hline Female (D) & 0.554 & & 0.578 & \\
\hline Married (D) & 0.604 & & 0.528 & \\
\hline Age & 39.736 & 10.36 & 41.855 & 10.647 \\
\hline Contrib. to $\mathrm{HH}$ inc. (\%) & 0.589 & 0.492 & 0.6 & 0.49 \\
\hline Age: $18-40$ in 1990 (D) & 0.631 & & 0.669 & \\
\hline Affected by reform (D) & 0.587 & & 0.472 & \\
\hline Exp.: own econ. sit. & 4.961 & 2.277 & 4.231 & 2.338 \\
\hline Pessimism & 3.397 & 2.545 & 3.608 & 2.577 \\
\hline Strong income fluctuations (D) & 0.323 & & 0.398 & \\
\hline Total net wealth (EUR) & 127,106 & 305,167 & 55,088 & 161,369 \\
\hline Exp.: German econ. sit. & 3.635 & 2.273 & 3.233 & 2.189 \\
\hline Financial literacy measure $1(\mathrm{D})^{13}$ & 0.725 & & 0.775 & \\
\hline Financial literacy measure $2(\mathrm{D})^{14}$ & 0.679 & & 0.757 & \\
\hline Financial literacy measure $3(\mathrm{D})^{15}$ & 0.54 & & 0.542 & \\
\hline \multicolumn{5}{|c|}{$\begin{array}{l}{ }^{13} \text { Correct answer to the question: Suppose that you have EUR } 100 \text { on your bank account. This money will give you a } 2 \% \\
\text { interest and you will leave it on that bank account for } 5 \text { years. What would you think: how much money will be on your bank account } \\
\text { after } 5 \text { years? The respondent could choose between three possible answers, one of which was correct. } \\
{ }^{14} \text { Correct answer to the question: Suppose that the money on your bank account yields an interest of } 1 \% \text { per year and that the } \\
\text { inflation rate is } 2 \% \text { per year. What do you think: After one year, could you buy as least as much, more, or less with your money } \\
\text { than today? The respondent could choose between three possible answers, one of which was correct. }\end{array}$} \\
\hline $\begin{array}{l}{ }^{15} \text { Correct answer to the question: Is the following c } \\
\text { safer return than investing your money in a fund." TI }\end{array}$ & $\begin{array}{l}\text { of false? "I } \\
\text { lent could }\end{array}$ & $\begin{array}{l}\text { sting your money } \\
\text { ose between thre }\end{array}$ & $\begin{array}{l}\text { igle sto } \\
\text { le ans }\end{array}$ & $\begin{array}{l}\text { general yields } \\
\text { one of which }\end{array}$ \\
\hline
\end{tabular}


Future planning measure ${ }^{16}$

$6.679 \quad 2.086$

6.861

1.974

Time preference measure ${ }^{17}$

2.506

5.9

2.533

\section{$\underline{\text { Job and health variables }}$}

Satisf. with work ${ }^{18}$

6.088

2.789

5.384

3.229

Exhausting activities (D)

0.655

0.633

Blue-collar worker (D)

0.171

0.171

White-collar worker (D)

0.296

0.277

Unemployed (D)

0.104

0.263

Unempl. rate in fed. state

9.894

2.212

16.323

4.103

Social insur. (D)

0.528

0.504

Social insur., self-empl. (D)

0.039

0.03

Marginal social insur. (D)

0.085

0.07

Risk-taking in sports \& leisure

3.861

2.828

3.673

2.822

Expected health

6.38

2.25

6.096

2.316

Smoker (D)

0.358

0.373

Life expectancy (years) $)^{19}$

78.284

8.383

$77.548 \quad 8.686$

Self-assessed health

2.235

0.769

$2.341 \quad 0.795$

Satisfaction with health

6.779

2.495

$6.614 \quad 2.36$

No. of GP visits

5.100

6.601

Been to hosp. (D)

0.138

0.118

Days in hosp.

1.354

5.801

1.303

6.029

Heart disease (D)

0.035

0.044

High blood pressure (D)

0.144

0.237

\footnotetext{
was correct.

${ }^{16}$ Individual appraisal on a scale between 0 and 10: degree of planning for the future.

${ }^{17}$ Individual appraisal on a scale between 0 and 10: degree of patience.

${ }^{18}$ If not stated otherwise, individual appraisals (e.g., satisfaction with work or health) are measured as a categorical variable of integers between 0 and 10 .

19 The variable life expectancy is measured in a complicated procedure consisting of three different survey questions. Respondents are asked, first, how they estimate the average life expectancy of their cohort for both genders separately. Second, they are asked whether they expect to live just as long, longer, or shorter than their cohort. In a third step, respondents are asked to estimate the number of years which they expect to live longer or shorter.
} 
High cholest. (D)

0.119

0.124

Stroke (D)

0.013

0.002

Lung disease (D)

0.068

0.064

Cancer (D)

0.036

0.04

Psychological illness (D)

0.064

0.078

Back problems (D)

0.182

0.191

Other illnesses (D)

0.264

0.301

Chronic illnesses (D)

0.364

0.404

Public pension account details

Year of first contribution

$1983.6 \quad 10.093$

$1981.8 \quad 10.951$

Non-contr. times, but recognised

$3.794 \quad 4.496$

$9.272 \quad 11.585$

Contribution/year in 2005

$75.970 \quad 30.059$

$63.116 \quad 18.149$

Contribution/year in 2004

$74.797 \quad 29.385$

$61.589 \quad 18.371$

Average time of unemployment in 2005

$13.187 \quad 9.008$

$18.770 \quad 13.207$

Average time of unemployment in 2004

$13.112 \quad 9.508$

$18.492 \quad 13.245$

No. of obs. 


\begin{tabular}{|c|c|c|c|c|}
\hline \multirow[b]{2}{*}{ Variable } & \multicolumn{2}{|c|}{ West } & \multicolumn{2}{|c|}{ East } \\
\hline & Mean & Std. Dev. & Mean & Std. Dev. \\
\hline Supporting the pension reform (D) & 0.299 & & 0.176 & \\
\hline Opinion: strong confl. between young and old (D) & 0.295 & & 0.347 & \\
\hline $\begin{array}{l}\text { Opinion: strong confl. between West and East } \\
\text { (D) }\end{array}$ & 0.406 & & 0.515 & \\
\hline Age (categories) ${ }^{20}$ & 6.364 & 2.397 & 6.756 & 2.431 \\
\hline Female (D) & 0.499 & & 0.496 & \\
\hline Expectation: Germany's economic sit. worse (D) & 0.259 & & 0.28 & \\
\hline Fed. elec. 2002: vote for CDU/CSU/SPD (D) & 0.704 & & 0.583 & \\
\hline Fed. elec. 2002: vote for Grüne (D) & 0.088 & & 0.055 & \\
\hline Fed. elec. 2002: vote for FDP (D) & 0.071 & & 0.051 & \\
\hline Fed. elec. 2002: vote for PDS (D) & 0.035 & & 0.193 & \\
\hline Married (D) & 0.642 & & 0.623 & \\
\hline Has children (D) & 0.681 & & 0.767 & \\
\hline Part-time or temp. job (D) & 0.145 & & 0.095 & \\
\hline In educ. or milit. service (D) & 0.064 & & 0.055 & \\
\hline Pensioner (D) & 0.203 & & 0.278 & \\
\hline Unemployed (D) & 0.029 & & 0.108 & \\
\hline Not working (spouse, pat. leave) (D) & 0.074 & & 0.036 & \\
\hline Employed (D) & 0.485 & & 0.428 & \\
\hline Highest school degree: upper secondary (D) & 0.704 & & 0.538 & \\
\hline University degree (D) & 0.006 & & 0.265 & \\
\hline Size of residential area (categories) ${ }^{21}$ & 4.531 & 2.477 & 4.074 & 2.554 \\
\hline No. of obs. & & 862 & & 472 \\
\hline
\end{tabular}

${ }^{20}$ Categories: $1=18-29 ; 2=21-24 ; 3=25-29 ; 4=30-34 ; 5=35-39 ; 6=40-44 ; 7=45-49 ; 8=$ $50-59 ; 9=60-69 ; 10=70$ and older.

${ }^{21}$ Categories: 1 = less or equal to 2,000 inhabitants; $2=$ more than 2,000 and less than or equal to 5,000 inhabitants; $3=$ more than 5,000 and less than or equal to 10,000 inhabitants; $4=$ more than 10,000 and less than or equal to 20,000 inhabitants; $5=$ more than 20,000 and less than or equal to 50,$000 ; 6=$ more than 50,000 and less than or equal to 100,000; $6=$ more than 100,000 and less than or equal to 500,$000 ; 7=$ more than 500,000 inhabitants. 
Table A.4: Regression results - Politbarometer

\begin{tabular}{|c|c|c|c|}
\hline \multirow{3}{*}{ Dep. var.: Supporting the pension reform } & \multirow{2}{*}{$\begin{array}{c}\text { Germany } \\
(1)\end{array}$} & \multirow{2}{*}{$\begin{array}{c}\text { West } \\
(2)\end{array}$} & \multirow{2}{*}{$\begin{array}{c}\text { East } \\
(3)\end{array}$} \\
\hline & & & \\
\hline & & & \\
\hline Eastern Germany (D) & $\begin{array}{c}-.386 \\
(.099)^{* * *}\end{array}$ & & \\
\hline Gender (D) & $\begin{array}{c}-.313 \\
(.088)^{* * *}\end{array}$ & $\begin{array}{c}-.253 \\
(.110)^{* *}\end{array}$ & $\begin{array}{c}-.444 \\
(.151)^{* * *}\end{array}$ \\
\hline Married (D) & $\begin{array}{l}.095 \\
(.091)\end{array}$ & $\begin{array}{c}.219 \\
(.113)^{*}\end{array}$ & $\begin{array}{l}-.161 \\
(.160)\end{array}$ \\
\hline Children (D) & $\begin{array}{c}-.312 \\
(.111)^{* * *}\end{array}$ & $\begin{array}{c}-.305 \\
(.136)^{* *}\end{array}$ & $\begin{array}{c}-.387 \\
(.196)^{* *}\end{array}$ \\
\hline Upper sec. degree (D) & $\begin{array}{c}.470 \\
(.103)^{* * *}\end{array}$ & $\begin{array}{c}.615 \\
(.118)^{* * *}\end{array}$ & $\begin{array}{l}.155 \\
(.224)\end{array}$ \\
\hline University degree (D) & $\begin{array}{c}.526 \\
(.170)^{* * *}\end{array}$ & & $\begin{array}{c}.401 \\
(.227)^{*}\end{array}$ \\
\hline Employed (D) & $\begin{array}{c}.009 \\
(.199)\end{array}$ & $\begin{array}{c}.059 \\
(.240)\end{array}$ & $\begin{array}{c}.314 \\
(.547)\end{array}$ \\
\hline Unemployed (D) & $\begin{array}{l}-.368 \\
(.298)\end{array}$ & $\begin{array}{l}-.595 \\
(.441)\end{array}$ & $\begin{array}{c}.062 \\
(.598)\end{array}$ \\
\hline Part-time or temp. empl. (D) & $\begin{array}{l}-.037 \\
(.228)\end{array}$ & $\begin{array}{c}.067 \\
(.275)\end{array}$ & $\begin{array}{l}-.065 \\
(.604)\end{array}$ \\
\hline Pensioner (D) & $\begin{array}{c}.220 \\
(.263)\end{array}$ & $\begin{array}{c}.280 \\
(.317)\end{array}$ & $\begin{array}{c}.500 \\
(.619)\end{array}$ \\
\hline Elec. 2002: CDU/CSU or SPD (D) & $\begin{array}{c}.292 \\
(.147)^{* *}\end{array}$ & $\begin{array}{c}.261 \\
(.178)\end{array}$ & $\begin{array}{c}.300 \\
(.271)\end{array}$ \\
\hline Exp.: own economic situation worse (D) & $\begin{array}{c}-.244 \\
(.094)^{* * *}\end{array}$ & $\begin{array}{c}-.260 \\
(.114)^{* *}\end{array}$ & $\begin{array}{l}-.180 \\
(.172)\end{array}$ \\
\hline Opinion: strong confl. betw. young and old (D) & $\begin{array}{c}.084 \\
(.087)\end{array}$ & $\begin{array}{c}.113 \\
(.106)\end{array}$ & $\begin{array}{l}-.020 \\
(.158)\end{array}$ \\
\hline Opinion: strong confl. betw. East and West (D) & $\begin{array}{l}-.139 \\
(.082)^{*}\end{array}$ & $\begin{array}{l}-.157 \\
(.101)\end{array}$ & $\begin{array}{l}-.025 \\
(.149)\end{array}$ \\
\hline Obs. & 1,334 & 862 & 472 \\
\hline
\end{tabular}

Source (data): Forschungsgruppe Wahlen (2007). 
Figure A.1: Differences in hand grip strength between East and West Germans

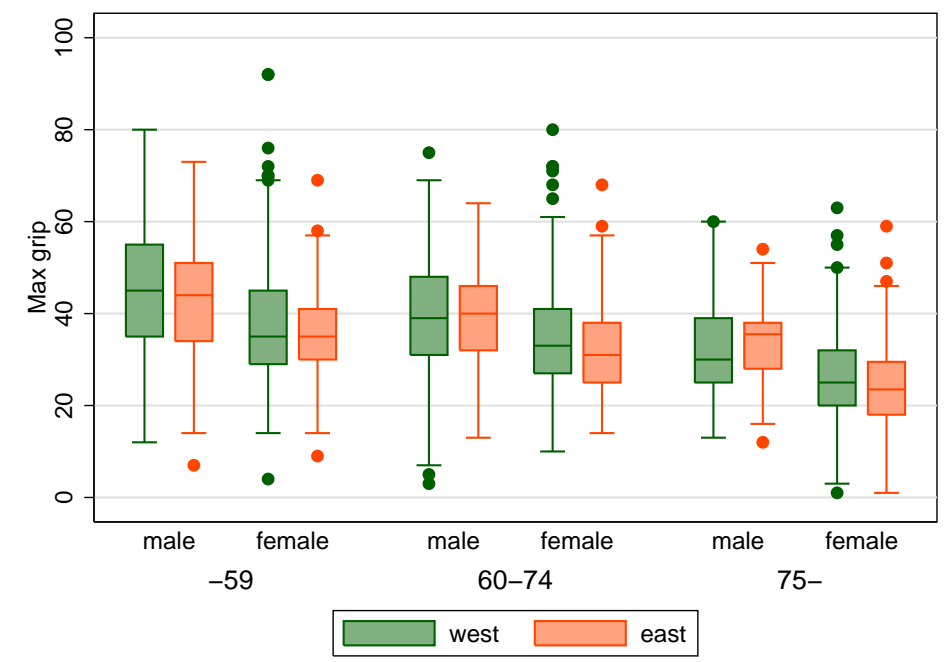

Source (data): SHARE (2008) 


\section{Discussion Paper Series}

Mannheim Research Institute for the Economics of Aging, Universität Mannheim

To order copies, please direct your request to the author of the title in question.

\begin{tabular}{|c|c|c|c|}
\hline Nr. & Autoren & Titel & Jahr \\
\hline $176-09$ & $\begin{array}{l}\text { Karsten Hank, Marcel } \\
\text { Erlinghagen }\end{array}$ & $\begin{array}{l}\text { Perceptions of Job Security in Europe's Ageing } \\
\text { Workforce }\end{array}$ & 09 \\
\hline $177-09$ & $\begin{array}{l}\text { Hendrik Jürges, } \\
\text { Karsten Hank, }\end{array}$ & $\begin{array}{l}\text { The Last Year of Life in Europe: Initial findings } \\
\text { from the SHARE study }\end{array}$ & 09 \\
\hline $178-09$ & Steffen Reinhold & $\begin{array}{l}\text { Reassessing the Link between Premarital } \\
\text { Cohabitation and Marital Instability }\end{array}$ & 09 \\
\hline $179-09$ & $\begin{array}{l}\text { Alexander Ludwig, } \\
\text { Edgar Vogel }\end{array}$ & $\begin{array}{l}\text { Mortality, Fertility, Education and Capital } \\
\text { Accumulation in a simple OLG Economy }\end{array}$ & 09 \\
\hline $180-09$ & Edgar Vogel & $\begin{array}{l}\text { From Malthus to Modern Growth: Child Labor, } \\
\text { Schooling and Human Capital }\end{array}$ & 09 \\
\hline $181-09$ & $\begin{array}{l}\text { Steffen Reinhold, } \\
\text { Hendrik Jürges }\end{array}$ & $\begin{array}{l}\text { Secondary School Fees and the Causal Effect } \\
\text { of Schooling on Health Behaviour }\end{array}$ & 09 \\
\hline $182-09$ & $\begin{array}{l}\text { Steffen Reinhold, } \\
\text { Kevin Thom }\end{array}$ & $\begin{array}{l}\text { Temporary Migration and Skill Upgrading: } \\
\text { Evidence from Mexican Migrants }\end{array}$ & 09 \\
\hline $183-09$ & $\begin{array}{l}\text { Hendrik Jürges, } \\
\text { Eberhard Kruk, Steffen } \\
\text { Reinhold }\end{array}$ & $\begin{array}{l}\text { The effect of compulsory schooling on health - } \\
\text { evidence from biomarkers }\end{array}$ & 09 \\
\hline 184-09 & $\begin{array}{l}\text { Nicola Fuchs- } \\
\text { Schündeln, Dirk } \\
\text { Krüger, Mathias } \\
\text { Sommer }\end{array}$ & $\begin{array}{l}\text { Inequality Trends for Germany in the Last Two } \\
\text { Decades: A Tale of Two Countries }\end{array}$ & 09 \\
\hline $185-09$ & $\begin{array}{l}\text { Francesco Cinnirella, } \\
\text { Joachim Winter }\end{array}$ & $\begin{array}{l}\text { Size Matters! Body Height and Labor Market } \\
\text { Discrimination: A Cross-European Analysis }\end{array}$ & 09 \\
\hline $186-09$ & $\begin{array}{l}\text { Hendrik Jürges, } \\
\text { Steffen Reinhold, } \\
\text { Martin Salm }\end{array}$ & $\begin{array}{l}\text { Does Schooling Affect Health Behavior? } \\
\text { Evidence from Educational Expansion in } \\
\text { Western Germany }\end{array}$ & 09 \\
\hline $187-09$ & Michael Ziegelmeyer & $\begin{array}{l}\text { Das Altersvorsorge-Verhalten von } \\
\text { Selbständigen - eine Analyse auf Basis der } \\
\text { SAVE-Daten }\end{array}$ & 09 \\
\hline $188-09$ & $\begin{array}{l}\text { Beatrice Scheubel, } \\
\text { Daniel Schunk, } \\
\text { Joachim Winter }\end{array}$ & $\begin{array}{l}\text { Don't raise the retirement age! An experiment } \\
\text { on opposition to pension reforms and East-West } \\
\text { differences in Germany }\end{array}$ & 09 \\
\hline
\end{tabular}

